include any endemics. Bird protection, and resident ornithologists are both wholly lacking in the islands, and although the goodwill of the authorities might well result in the setting up of some reserves and sanctuaries, they would be ineffective without somebody to police them. The Bannermans make out a good case for such intervention, and it is to be hoped that the International Council for Bird Preservation will take steps to see that not only are reserves set up, but wardens appointed to guard them.

RICHARD FITTER

\title{
Birds of the Atlantic Ocean paintings by Keith Shackleton, text by Ted Stokes. Country Life, $£ 66 \mathrm{~s}$.
}

This handsome volume, in a series that benefits the World Wildlife Fund, includes photographs of 15 oil paintings, each devoted to a single species, and 23 plates of drawings in gouache grouping several related species which are admirably devised for their purpose of identification. With the text Commander Stokes has made a very adequate contribution, in part by means of compilation inevitable in dealing with some of the less familiar birds, with accounts that are clear and concise, and accompanied by most useful distribution maps. His account of the status of the cahow (the Bermuda petrel) will be disturbing to conservationists.

Keith Shackleton regrets that ocean birds have no gaudy plumage, but his paintings reveal that many of them in their plumage-white, brown, grey, black - follow the injunction of Polonius to be 'rich, not gaudy,' while, as Prince Philip aptly says in his foreword, the artist has captured 'the grace and ease of flight' which characterises all sea-birds. The plate of the little terns I find least satisfactory, perhaps through some fault in the colour-printing, and rather overcrowded. The rest are a sheer delight - the Arctic skuas, the fulmar, the white-tailed tropic bird, the northern gannet, and pre-eminently the wandering albatross - the real albatross, the albatross of the Ancient Mariner. If any ornithologist does not already know that famous and moving poem by heart, this painting may persuade him to learn it.

HURCOMB

\section{Seabirds of the Tropical Atlantic Ocean by George E. Watson,} $\$ 3.75$.

\section{Seabirds of the Tropical Pacific Ocean by Warren B. King, free;} both from Smithsonian Institution, Washington D.C.

The purpose of the 'Smithsonian Identification Manuals' is to assist 'reliable identification of organisms in little known parts of the world which are not otherwise covered in readily available handbooks'. Of these two the Atlantic one is a hard-cover second edition, the Pacific a paperback classified as 'preliminary'. Both are printed photographically from typescript and from pen, ink and wash drawings by Tina $A$. Clapp which illustrate most of the species described, with results that are as satisfactory as they are economical. Both drawings and text, which are properly cross-referenced, are of a high quality.

The care taken in preparation, supported by full consultation of authorities and testing in the field (if such an expression may be used of great oceans), is such that the books can be unreservedly recommended to all land-based or shipboard seabird watchers. All species known to occur in the Atlantic between $33^{\circ} \mathrm{N}$ and $35^{\circ} \mathrm{S}$ and in the central Pacific (west of the line Hawaii-Easter Island) between the $30^{\circ}$ parallels are included, representing a sizeable sample of the birds of the two oceans as a whole - in fact 107 for the Pacific and 115 (plus brief notes on a further 15 'strays') for the Atlantic. Mr Watson's descriptions are admirably succinct, while Mr King, though a little more wordy, includes 34 distribution 
maps, in which breeding localities are indicated by arrows. Co-ordination between the two books though not quite faultless is generally very good.

It is to be regretted that the identical section in each book headed 'preserving and shipping specimens', does not make clear that many seabirds 'stranded' on ships or on the land in storms or dark nights are in fact uninjured and can be satisfactorily recorded, identified with the aid of modern photographic equipment and released without ending up in a museum drawer. The collection of specimens should be the exception and not the rule and generally confined to dead birds or those injured beyond recovery. But this is a minor blemish in a pair of extremely serviceable books, which are a model of what such books should be.

HUGH F. I. ELLIOTT

\section{Night Watchmen of Bush and Plain by David Fleay. Jacaranda Press, Brisbane, $\$ 5.50$. \\ Birds of Australia by Stanley Breeden and Peter Slater. Angus \& Robertson, 55s.}

As a former Curator of the Melbourne Zoo and Director of the Healesville Wildlife Sanctuary outside Melbourne, David Fleay is well qualified to write about Australian birds and mammals. The first section of this book on 'owls and owl-like birds' records 40 years' devotion to the powerful owl, Ninox strenua, from the day when a schoolboy was attracted to a mysterious call in the forest, through the struggles and heartbreaks of trying to rear them in captivity, culminating in successful breeding only after the book had gone to press. The chatty style and some irrelevant reminiscing in this section may not appeal to all readers but cannot detract from the wealth of information on many aspects of the bird's biology. The breeding is annotated from the pairing of birds in the wild, to the fledging of young in captivity, with details of the various calls, the diet, the changes of plumage and the ailments to which powerful owls are susceptible. The second part is a more impersonal account of the other Australian owls - the frogmouth, owlet-nightjar and nightjars - based again on experience of the birds in the wild and in captivity.

The whole is most admirably illustrated by 12 pages of colour photographs and over 80 in black-and-white, many being close-up portraits of the various species in different stages of plumage. The interest of readers would be stimulated if cross-references were supplied between the photographs and the text, and the value of the book for reference would be enhanced if the plates were indexed: but these are minor criticisms of an excellent book.

The second book introduces Australian birds first by showing their place in the world context; next by chapters on courtship and nesting, raising the young, and feeding; finally in groups by habits and habitats - in rivers and lakes, at night, in rainforests, in the inland, in eucalypt forest, and on ocean and shore. The chapters are profusely illustrated by photographs, including 16 pages in colour, and by Peter Slater's black-and-white drawings, in all depicting over 200 species. The photographs are drawn from the author's own collections and from those of 30 of the leading wildlife photographers in the country, so the quality is excellent and they are particularly exciting in depicting some of the rarer as well as the more familiar birds.

The text suffers from being fitted into the pages where space can be found, but it is unpretentious and informative. The captions to the photographs are perhaps the least successful part of the book, with a tendency to over-generalise, and they are not always easy to correlate with the right pictures. Some clarity seems to have been sacrificed to produce the aesthetically pleasing result. In compensation there is a good index to the illustrations.

B. P. HALL 